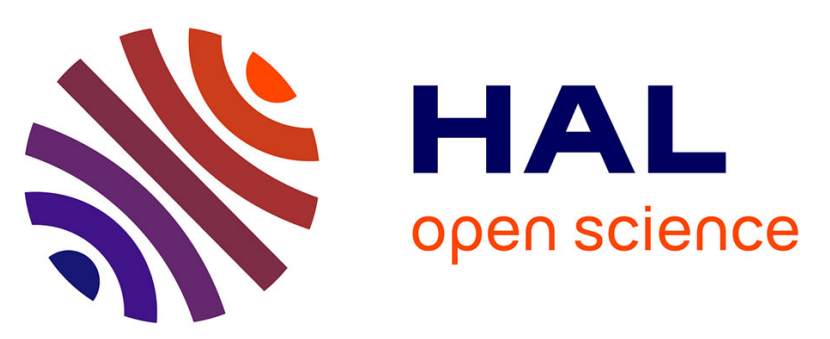

\title{
Impact of the IDEA Collaboration Study Results on Clinical Practice in France for Patients With Stage III Colon Cancer: A National GERCOR - PRODIGE Survey
}

Kaïssa Ouali, Anthony Turpin, Cindy Neuzillet, Benoît Rousseau, Marie Line Garcia-Larnicol, Christophe Tournigand, Emmanuelle Samalin, Julien Taieb, Thierry André, Romain Cohen

\section{- To cite this version:}

Kaïssa Ouali, Anthony Turpin, Cindy Neuzillet, Benoît Rousseau, Marie Line Garcia-Larnicol, et al.. Impact of the IDEA Collaboration Study Results on Clinical Practice in France for Patients With Stage III Colon Cancer: A National GERCOR - PRODIGE Survey. Clinical Colorectal Cancer, 2021, 20 (1), pp.79-83.e4. 10.1016/j.clcc.2020.11.004 • hal-03171242

\author{
HAL Id: hal-03171242 \\ https://hal.science/hal-03171242
}

Submitted on 7 Jul 2021

HAL is a multi-disciplinary open access archive for the deposit and dissemination of scientific research documents, whether they are published or not. The documents may come from teaching and research institutions in France or abroad, or from public or private research centers.
L'archive ouverte pluridisciplinaire HAL, est destinée au dépôt et à la diffusion de documents scientifiques de niveau recherche, publiés ou non, émanant des établissements d'enseignement et de recherche français ou étrangers, des laboratoires publics ou privés. 


\section{Original research}

\section{Title:}

3 Impact of the IDEA collaboration study results on clinical practice in France for stage III colon 4 cancer patients: a national GERCOR - PRODIGE survey

\section{Short title:}

6 IDEA collaboration results in real-life practice

\section{Authors:}

8 Kaïssa Ouali ${ }^{1}$, Anthony Turpin ${ }^{2}$, Cindy Neuzillet ${ }^{3}$, Benoît Rousseau ${ }^{4}$, Marie-Line Garcia-

9 Larnicol $^{5}$, Christophe Tournigand ${ }^{6}$, Emmanuelle Samalin ${ }^{7}$, Julien Taieb ${ }^{8}$, Thierry André 9 ,

10 Romain Cohen ${ }^{9}$

\section{Affiliations:}

$12{ }^{1}$ Medical oncology department, Saint-Antoine hospital, AP-HP, Paris, France,

$13 \quad 2$ Medical oncology department, CHRU Lille, Lille, France

$14{ }^{3}$ Medical oncology department, Curie Institute, Versailles Saint-Quentin University, Saint 15 Cloud, France,

$16{ }^{4}$ Department of Medicine - Solid Tumor Division, Memorial Sloan Kettering Cancer Center,

17 New York, USA,

$18{ }^{5}$ GERCOR,

$19{ }^{6}$ Medical oncology department, Henri Mondor hospital, Créteil, France,

$20{ }^{7}$ Medical oncology Departement, Institut du Cancer de Montpellier (ICM)/ Institut de

21 Génomique Fonctionnelle, CNRS, INSERM, Univ. Montpellier, Montpellier, France, 
$22{ }^{8}$ Gastroenterolgy and GI oncology, Georges Pompidou European Hospital, APHP, Sorbonne

23 Paris Cité, Paris Descartes University, Paris, France

$24{ }^{9}$ Sorbonne University and medical oncology department, Saint-Antoine hospital, AP-HP, Paris,

25 France,

26 Corresponding Author: Dr Romain Cohen; ORCID 0000-0001-9602-5162

27 Hôpital Saint-Antoine, 184 rue du faubourg Saint-Antoine, 75012 Paris, France

28 Tel: +33 1492823 36; Fax: +33 1492834 98; email address: romain.cohen@aphp.fr

29 Funding: none

30 Conflict of interest statement:

31 BR has received honoraria for speaker or advisory role from Astellas, Bayer, Gilead, Novartis,

32 Roche Astellas, received research funding from Roche/Foundation Medicine and travel, 33 accommodations and expenses from Bayer, Servier.

$34 \mathrm{CN}$ has received honoraria for speaker or advisory role from Servier, AstraZeneca, Amgen,

35 Merck, Novartis, Incyte, Baxter, MSD, received research funding from Roche/Foundation

36 Medicine and travel, accommodations and expenses from OSE Immunotherapeutics, MSD,

37 Merck, Mylan.

38 ES receiving honoraria from Pierre Fabre, Roche, Servier, Amgen, Sanofi, Bristol-Myers

39 Squibb, MSD Oncology and travel from Servier, Roche, MSD, Amgen.

40 JT received honoraria for speaker or advisory role and travel and accommodation grants from

41 celgene, roche, merck, MSD, Lilly, HalioDX, Sanofi, Amgen, Servier, Pierre Fabre and Sirtex.

$42 \mathrm{RC}$ has received honoraria from Amgen, Sanofi and Servier, and travel fees from Sanofi. 
43 TA reported receiving consulting or advisory role and or honoraria from Bristol-Myers Squibb, 44 Clovis, HalioDX, MSD Oncology, Pierre Fabre, Roche/ Genentech/Ventana, Sanofi, Servier,

45 Teasaro, speakers' bureau for Bristol-Myers Sqiubb and Servier; travel, accommodations, and 46 expenses from: Amgen, Bristol-Myers Squibb, Roche, Ventana.

47 All remaining authors have declared no conflicts of interest.

48 Keywords: adjuvant chemotherapy; colorectal neoplasms; FOLFOX; CAPOX; guidelines; 


\section{MICRO-ABSTRACT}

50 The IDEA study showed that the type and duration of adjuvant chemotherapy might be adjusted

51 according to level of risk in stage III colon cancer. Hereby, we show that it has been mainly

52 integrated in routine practice in France with a switch from six to three months and from

53 FOLFOX to CAPOX regimen in low-risk stage III colon cancer patients. 


\section{CLINICAL PRACTICE POINTS}

55 The prospective, pre-planned pooled analysis of six concurrently conducted randomized phase

56 III trials (IDEA collaboration) was built to evaluate the non-inferiority of three months of

57 adjuvant treatment with oxaliplatin plus fluoropyrimidine to the six-month standard duration of

58 therapy for stage III colon cancer patients. Although the non-inferiority was not confirmed in

59 the overall population, the IDEA study showed that the type (and duration of treatment may be

60 adjusted according to the level of risk (low risk pT1-3/N1 versus high risk pT4 and/or N2).

61 We realized a nationwide survey in France, one year after the publication of the IDEA

62 collaboration results. We show that a shortened duration of adjuvant treatment using CAPOX

63 for three months has been integrated in France as standard of care for low risk stage III colon

64 cancer patients by most physicians. Six months of FOLFOX remains the standard treatment for 65 the high-risk population. 


\section{ABSTRACT}

67 Background: The IDEA collaboration showed that the type and duration of adjuvant chemotherapy in stage III colon cancer (CC) could be adjusted according to level of risk. We imed at evaluating the implementation of IDEA's results in real-life practice for stage III CC.

70 Material and methods: All clinicians registered in the French oncology cooperative groups

71 GERCOR, FFCD and UNICANCER GI mailing lists were invited to participate to an online 72 anonymized nationwide survey from January 30, 2019 to March 31, 2019. Proportions were 73 compared using chi-squared test.

74 Results: A total of 213 physicians answered the survey. $173(81 \%)$ considered that three 75 months of adjuvant chemotherapy was the new standard of care for low risk (pT1-3/N1) stage 76 III CC and $99 \%$ that six months remained the standard of care for high risk (pT4 and/or pN2) 77 stage III CC. In patients under 70 years, CAPOX for three months was prescribed by $74 \%$ of 78 the participants in low risk CC while six months of FOLFOX was preferred for high risk CC in $7994 \%$ cases. For patients over 70 years with good performance status and no comorbidities, 172 80 physicians (81\%) prescribed oxaliplatin-based chemotherapy for low risk CC (3 months: 144 81 out of 172, 88\%), and 200 physicians (94\%) prescribed oxaliplatin-based adjuvant 82 chemotherapy for high risk CC (6 months: 199 out of 200, 99\%).

83 Conclusion: IDEA results have been practice changing as French physicians have implemented 84 three months CAPOX for low risk stage III CC patients, substituting six months FOLFOX 85 which remains the preferred regimen for high risk patients. 
87 Six months of adjuvant chemotherapy with oxaliplatin plus a fluoropyrimidine has been the standard of care for stage III colon cancer (CC) patients since 2004 (1-4). However, the cumulative neurotoxicity related to the use of oxaliplatin led to the evaluation of a shortened 90 duration of adjuvant chemotherapy in this setting.

91 The IDEA (International Duration Evaluation of Adjuvant Therapy) collaboration study 92 showed that the type and duration of adjuvant chemotherapy in stage III CC might be adjusted 93 according to the level of risk (low risk: pT1-3 and pN1; high risk: pT4 and/or pN2) (5). 94 Although the study did not demonstrate the non-inferiority of three months versus six months 95 of adjuvant chemotherapy in the overall population for Disease Free Survival (DFS) (HR 1.07, $9695 \%$ confidence interval $(95 \% \mathrm{CI}) 1.00-1.15)$, the non-inferiority of CAPOX (capecitabine plus 97 oxaliplatin) for three months was demonstrated for low risk stage III CC patients, which 98 represent $59 \%$ of the entire stage III population.

99 International guidelines $(6)(7)(8)$ have been updated accordingly but data concerning the Commenté [RC1]: Réf à fusionner 100 implementation of IDEA conclusions in real-life adjuvant chemotherapy prescriptions are 101 lacking. We aimed at assessing the impact of IDEA study on daily practice for stage III CC in 102 France.

\section{MATERIAL AND METHODS}

104 Physicians registered in three French cooperative groups (FFCD, Fédération Francophone de 105 Cancérologie Digestive; GERCOR, French Multidisciplinary Group in Oncology; UCGI, 106 Unicancer Gastrointestinal Group) were invited to fill in an online questionnaire 107 (supplementary material). Reminder emails were sent every 2 weeks. The survey was composed 108 of 24 questions, related to daily practices. Clinicians were asked which modality of adjuvant 
117213 physicians participated to the survey from January 30, 2019 to March 31, 2019.

118 Demographic characteristics are displayed in Table 1. 198 of them completed the survey in its 127 only) (figure 1).

128 For high-risk stage III CC patients, 94\%, 6\% and $0.5 \%$ of physicians prescribed FOLFOX for six months, CAPOX for six months or FOLFOX for three months, respectively. chemotherapy (FOLFOX or CAPOX, three months or six months) they would choose in different clinical settings. A 5-point Likert scale was also used (from 1, strongly disagree, to 5 , strongly agree) to evaluate IDEA's impact on their daily clinical practice. Participants were also asked to indicate the preferred venous access (peripheral or central access) and device (PICCentirety. $63 \%$ of the participants agreed or strongly agreed that IDEA study had an impact on their clinical practice, whereas $17 \%$ disagreed or strongly disagreed. $75 \%$ declared that three months of CAPOX was the new standard of care for low risk stage III CC and $99 \%$ that six months of adjuvant chemotherapy remained the standard of care for the high risk population.

\section{Patients under 70 years}

For low-risk stage III CC patients adjuvant chemotherapy was prescribed for 3 months by $84 \%$ of the responders, with a majority of CAPOX regimen (75\% vs. $8 \%$ with FOLFOX); a sixmonth duration of adjuvant chemotherapy was chosen by $16 \%$ of physicians (with FOLFOX

130 Patients over 70 years (figure 2) 
132 For patients $>70$ with good PS and low risk stage III CC, oxaliplatin-based chemotherapy was 133 prescribed by $81 \%$ of physicians, for three $(68 \%)$ or six months $(13 \%) .18 \%$ of responders 134 chose fluoropyrimidine monotherapy for three (3\%) or six months $(15 \%)$.

135 In case of high-risk stage III CC, adjuvant chemotherapy was prescribed for six months by $99 \%$ of responders, mainly with doublets (94\% while $6 \%$ chose fluoropyrimidine monotherapy). $\underline{\text { ECOG PS }>1 \text { and/or with comorbidities }}$

138 In older patients with altered PS or comorbidities, in case of low-risk stage III CC, $13 \%, 61 \%$, 139 and $25 \%$ of the participants declared to prescribe no adjuvant chemotherapy, fluoropyrimidine 140 monotherapy, or oxaliplatin-based chemotherapy, respectively. Oxaliplatin-based adjuvant 141 chemotherapy was proposed for three months by most clinicians (65\%).

142 In the high-risk population with ECOG PS > 1 or comorbidities, 3\%, 44\% and $51 \%$ declare to 143 prescribe no adjuvant chemotherapy, a fluoropyrimidine alone, or oxaliplatin-based 144 chemotherapy (94\% for 6 months), respectively.

\section{Venous access}

146 In patients with appropriate venous capital, CAPOX for three months was administered without 147 central venous access device (CVAD) for two third (66\%) of the participants, using an 148 implantable port $(21 \%)$ or a PICC-line (12\%). 


\section{DISCUSSION}

Our study is the first to report real life practices for stage III CC patients after the publication of the IDEA study. We show that the modulation of adjuvant chemotherapy duration and type according to the level of risk has been adopted as standard of care in France for stage III CC.

Our results are in line with a survey realized among the Australia and New Zealand SCOT's participants. It reported that the expected minimum survival benefit warranted to choose a sixmonth ACT rather than three-month duration was much larger than the estimates of the IDEA trial (9). One might have hypothesized that the CAPOX might not be easily integrated into daily practice in France since FOLFOX was prescribed by a vast majority of French physicians before $(90 \%$ in the IDEA France trial (10)). Although the FOLFOX regimen remained largely prescribed for high-risk stage III CC patients, the combination of capecitabine and oxaliplatin was the main choice for low risk stage III CC patients in this survey, showing how much impact IDEA had on real-life patients' care.

Oxaliplatin-based adjuvant chemotherapy was mostly prescribed for older patients with good PS (80\%-90\%) and, to a lesser extent, for patients with comorbidities and high-risk CC (50\%). However, there is no clear evidence that the addition of oxaliplatin to fluoropyrimidine is associated with an improvement of DFS or overall survival, as it has been shown in a pooled analysis of MOSAIC, NSABP C-07 and XELOXA trials $(\mathrm{N}=1119$; DFS hazard ratio $(\mathrm{HR})=$ 0.94, 95\% confidence interval $(95 \% \mathrm{CI}) \quad 0.78-1.13$ and $\mathrm{OS} \mathrm{HR}=1.04,95 \% \mathrm{CI} 0.85-1.27)$ (12,13). Though, another analysis from NSABP C-08, XELOXA, X-ACT and AVANT trials did detect a significant improvement of DFS and OS in patients $>70$ treated with XELOX or FOLFOX (14). The prescription of doublet adjuvant chemotherapy in fit elderly patients observed in our survey remains to be properly evaluated in dedicated clinical trials, such as the 2 PRODIGE 34 phase III study (NCT023553790). 
190 To conclude, adjuvant chemotherapy with CAPOX for three months has been mainly integrated

One third of the physicians used CVAD for patients treated with CAPOX for three months, despite good venous capital. The feasibility of treating patients with CAPOX on a peripheral venous access for three or six months has been demonstrated in an analysis of 203 patients included in the IDEA France study: CAPOX adjuvant chemotherapy without a CVAD was successful in $88.4 \%$ of patients for whom chemotherapy had been planned without the use of CVAD (15). The reasons for such a high use of central venous devices need to be explored.

Our study exhibits several weaknesses. First, the study population might have been biased by its selection through the cooperative groups networks, even if it is representative of the current 81 French medical demography (16), with physicians working in different types of institution, with various levels of experience and different medical specialty backgrounds. We acknowledge that the declarative nature of our study might have biased the results. We observed that the use of CAPOX for 3 months was lower than the proportion of physicians declaring this treatment as the new standard of care: $44 \%$ of physicians declared they had prescribed it for their last 5 patients with low risk stage III tumor while $75 \%$ of them considered CAPOX 3 months as the new standard of care for this population. Therefore, analyses of prospective cancer registries are required to validate our study. Besides, it would be interesting to evaluate if the recent release of OS data from the IDEA study reinforced the observed changes in routine practice(17).

192 preferred choice of prescribers for high-risk patients in France.

191 as a new standard of care for low-risk stage III CC. FOLFOX for six months remains the 


\section{BIBLIOGRAPHY}

2 1. André T, Boni C, Mounedji-Boudiaf L, Navarro M, Tabernero J, Hickish T, et al. Oxaliplatin, Fluorouracil, and Leucovorin as Adjuvant Treatment for Colon Cancer. N Engl J Med. 2004 Jun 3;350(23):2343-51.

5 2. Kuebler JP, Wieand HS, O'Connell MJ, Smith RE, Colangelo LH, Yothers G, et al. Oxaliplatin combined with weekly bolus fluorouracil and leucovorin as surgical adjuvant chemotherapy for stage II and III colon cancer: results from NSABP C-07. J Clin Oncol Off J Am Soc Clin Oncol. 2007 Jun 1;25(16):2198-204.

3. André T, Boni C, Navarro M, Tabernero J, Hickish T, Topham C, et al. Improved overall survival with oxaliplatin, fluorouracil, and leucovorin as adjuvant treatment in stage II or III colon cancer in the MOSAIC trial. J Clin Oncol Off J Am Soc Clin Oncol. 2009 Jul 1;27(19):3109-16.

4. Haller DG, Tabernero J, Maroun J, de Braud F, Price T, Van Cutsem E, et al. Capecitabine plus oxaliplatin compared with fluorouracil and folinic acid as adjuvant therapy for stage III colon cancer. J Clin Oncol Off J Am Soc Clin Oncol. 2011 Apr 10;29(11):1465-71.

5. Grothey A, Sobrero AF, Shields AF, Yoshino T, Paul J, Taieb J, et al. Duration of Adjuvant Chemotherapy for Stage III Colon Cancer. N Engl J Med. 2018 Mar 29;378(13):1177-88.

0 6. Costas-Chavarri A, Nandakumar G, Temin S, Lopes G, Cervantes A, Cruz Correa M, et al. Treatment of Patients With Early-Stage Colorectal Cancer: ASCO ResourceStratified Guideline. J Glob Oncol. 2019;5:1-19.

7. Benson AB, Venook AP, Al-Hawary MM, Cederquist L, Chen Y-J, Ciombor KK, et al. NCCN Guidelines Insights: Colon Cancer, Version 2.2018. J Natl Compr Cancer Netw JNCCN. 2018 Apr;16(4):359-69.

8. Labianca R, Nordlinger B, Beretta GD, Mosconi S, Mandalà M, Cervantes A, et al. Early colon cancer: ESMO Clinical Practice Guidelines for diagnosis, treatment and follow-up. Ann Oncol Off J Eur Soc Med Oncol. 2013 Oct;24 Suppl 6:vi64-72.

9 9. Blinman PL, Martin AJ, Jefford M. Patients' preferences for 3 months versus 6 months of adjuvant chemotherapy (ACT) for colon cancer in the SCOT trial: what survival benefits make longer chemotherapy worthwhile? Journal of Clinical Oncology: Official Journal of the American Society of Clinical Oncology, 36 (suppl; abstr 3602). 2018 May 20;

10. André T, Vernerey D, Mineur L, Bennouna J, Desrame J, Faroux R, et al. Three Versus 6 Months of Oxaliplatin-Based Adjuvant Chemotherapy for Patients With Stage III Colon Cancer: Disease-Free Survival Results From a Randomized, Open-Label, International Duration Evaluation of Adjuvant (IDEA) France, Phase III Trial. J Clin Oncol Off J Am Soc Clin Oncol. 2018 20;36(15):1469-77.

11. Munaf Al-Kadhimi MEH, Oncology Consultants P. A H, Rush University Medical Center C, Northshore University Health System E, Evanston Northwestern HP, 
Northwestern Memor Hosp L, et al. Ambulatory 5FU infusion pumps: Patient perceptions and quality of life. J Clin Oncol Off J Am Soc Clin Oncol 37 Suppl Abstr 663. 2019 Jan 19;

12. Goldberg RM, Tabah-Fisch I, Bleiberg H, de Gramont A, Tournigand C, Andre T, et al. Pooled analysis of safety and efficacy of oxaliplatin plus fluorouracil/leucovorin administered bimonthly in elderly patients with colorectal cancer. J Clin Oncol Off J Am Soc Clin Oncol. 2006 Sep 1;24(25):4085-91.

13. McCleary NJ, Meyerhardt JA, Green E, Yothers G, de Gramont A, Van Cutsem E, et al. Impact of age on the efficacy of newer adjuvant therapies in patients with stage II/III colon cancer: findings from the ACCENT database. J Clin Oncol Off J Am Soc Clin Oncol. 2013 Jul 10;31(20):2600-6.

14. Haller DG, O’Connell MJ, Cartwright TH, Twelves CJ, McKenna EF, Sun W, et al. Impact of age and medical comorbidity on adjuvant treatment outcomes for stage III colon cancer: a pooled analysis of individual patient data from four randomized, controlled trials. Ann Oncol Off J Eur Soc Med Oncol. 2015 Apr;26(4):715-24.

15. Lapeyre-Prost A, Hug de Larauze M, Chibaudel B, Garcia ML, Guering-Meyer V, Bouché $\mathrm{O}$, et al. Feasibility of Capecitabine and Oxaliplatin Combination Chemotherapy Without Central Venous Access Device in Patients With Stage III Colorectal Cancer. Clin Colorectal Cancer. 2016;15(3):250-6.

16. La démographie médicale [Internet]. Conseil National de l'Ordre des Médecins. 2019 [cited 2019 Oct 3]. Available from: https://www.conseil-national.medecin.fr/lordremedecins/conseil-national-lordre/demographie-medicale

17. Sobrero AF, Andre T, Meyerhardt JA, Grothey A, Iveson T, Yoshino T, et al. Overall survival (OS) and long-term disease-free survival (DFS) of three versus six months of adjuvant (adj) oxaliplatin and fluoropyrimidine-based therapy for patients (pts) with stage III colon cancer (CC): Final results from the IDEA (International Duration Evaluation of Adj chemotherapy) collaboration. J Clin Oncol. 2020 May 20;38(15_suppl):4004-4004. 


\section{FIGURES AND TABLES CAPTIONS}

2 Table 1: Population characteristics

3 Figure 1: Type and duration of adjuvant chemotherapy for patients under 70 with low risk stage

4 III colon cancer

5 Figure 2: Type and duration of chemotherapy for patients $>70$ with low risk or high risk stage

6 III colon cancer, depending on performance status and comorbidities 
$\underline{\text { Table } 1 \text { : Population characteristics }}$

\section{N (\%)}

Participants $213(100)$

Specialty

$\begin{array}{lc}\text { Gastroenterologist } & 109(51.2) \\ \text { Medical oncologist } & 84(39.4) \\ \text { Radiation therapist } & 10(4.7) \\ \text { Surgeon } & 10(4.7)\end{array}$

Workplace

$\begin{array}{lc}\text { Academic hospital } & 65(30.5) \\ \text { General Hospital } & 57(26.8) \\ \text { Comprehensive cancer center } & 56(26.3) \\ \text { Private clinic } & 35(16.4)\end{array}$

Experience in gastro-intestinal cancers

$\begin{array}{ll}<5 \text { years } & 28(13.1) \\ 5-10 \text { years } & 40(18.8) \\ 10-20 \text { years } & 75(35.2) \\ >20 \text { years } & 70(32.9)\end{array}$

Number of stage III colon cancer patients
$<4$ per year
$10(4.7)$
4 - 8 per year
$53(24.9)$
$8-12$ per year
$51(23.9)$
$>12$ per year
$99(46.5)$ 
Figure 1: Type and duration of adjuvant chemotherapy for patients under 70 with low risk stage III colon cancer.

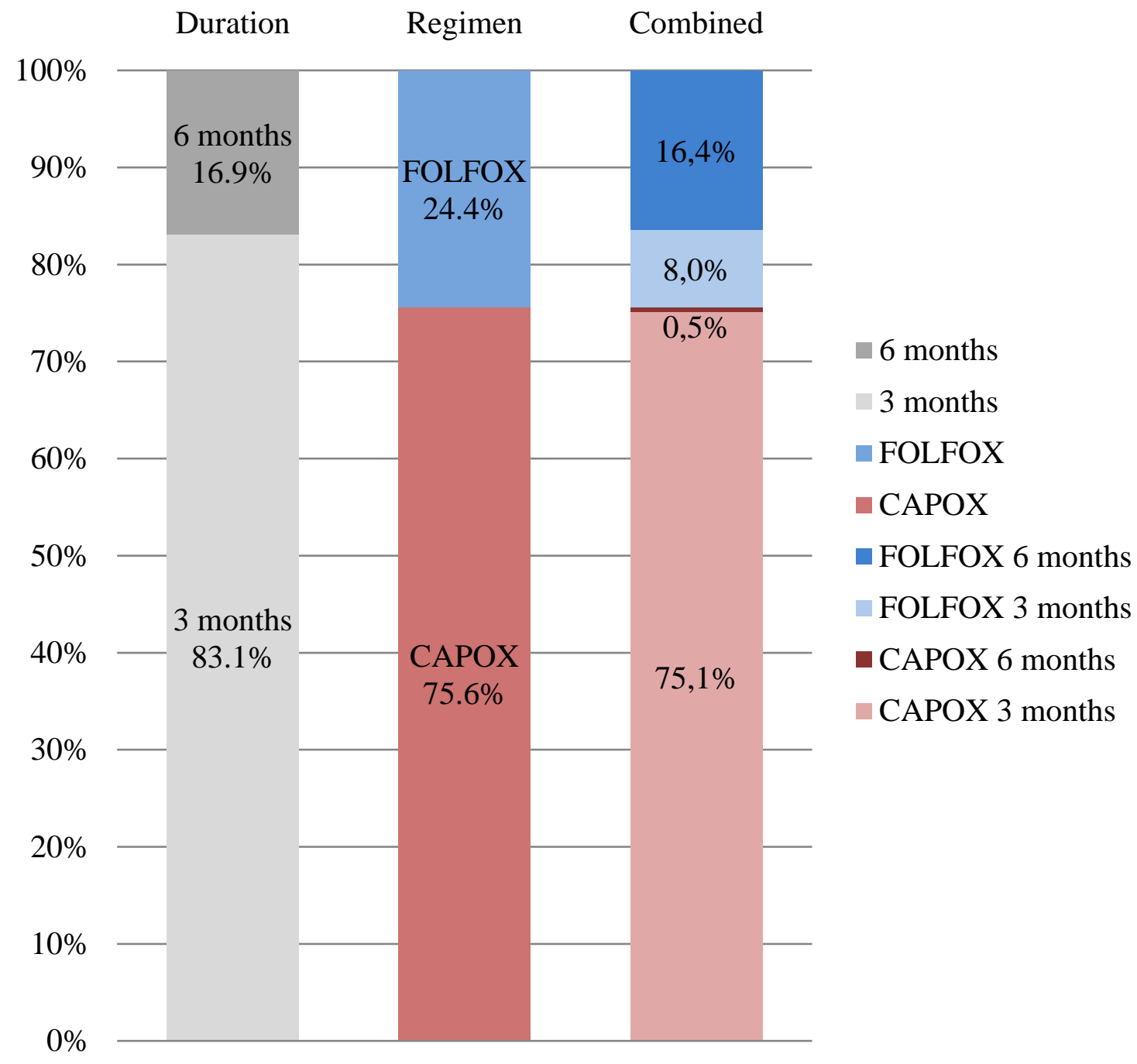


Figure 2: Type and duration of chemotherapy for patients $>70$ with low risk or high risk stage

III colon cancer, depending on performans status and comorbidies

Panel A: Performans score 0-1 and no comorbidity

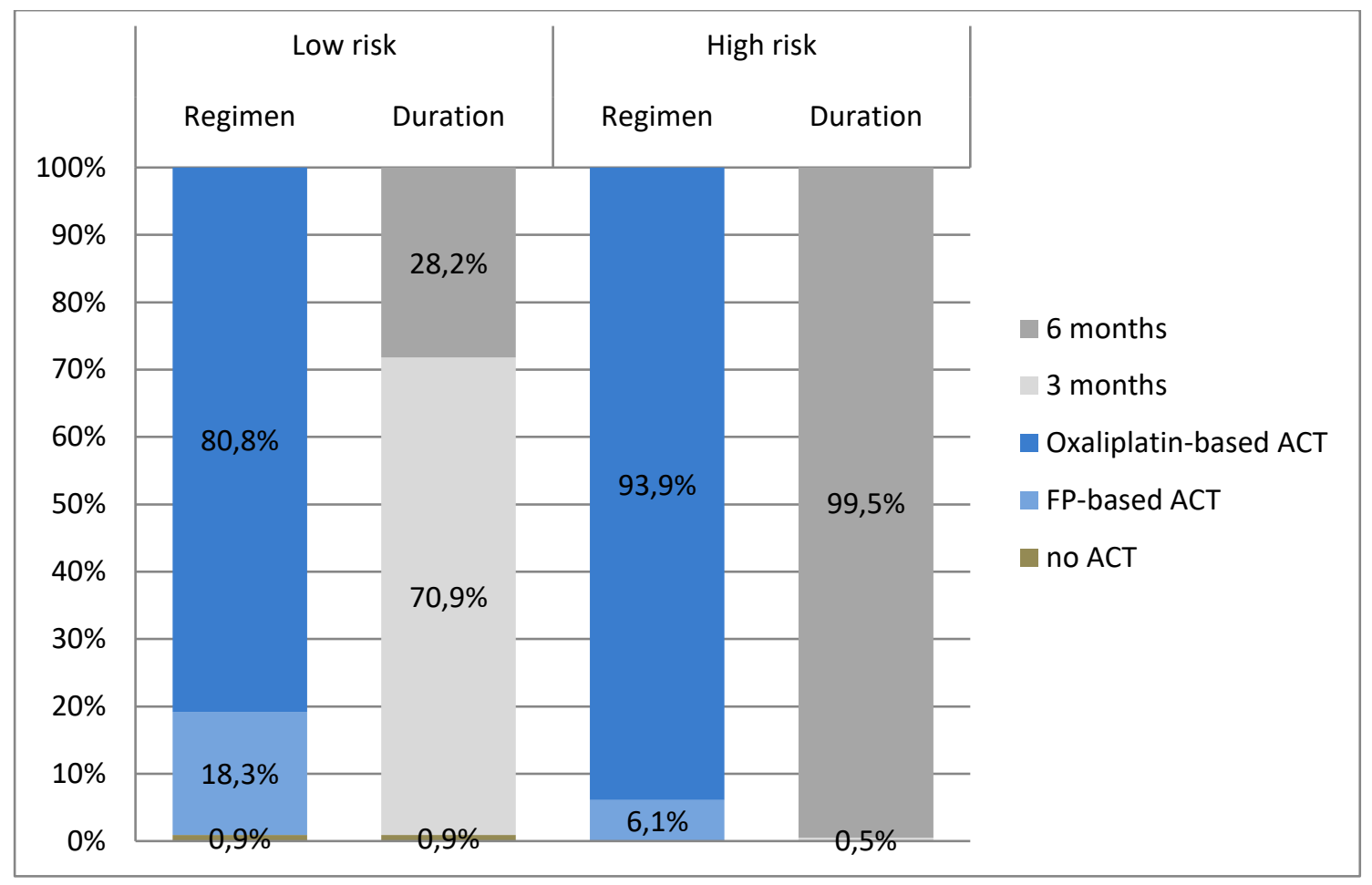

Panel B: Performans score > 1 and/or comorbidity

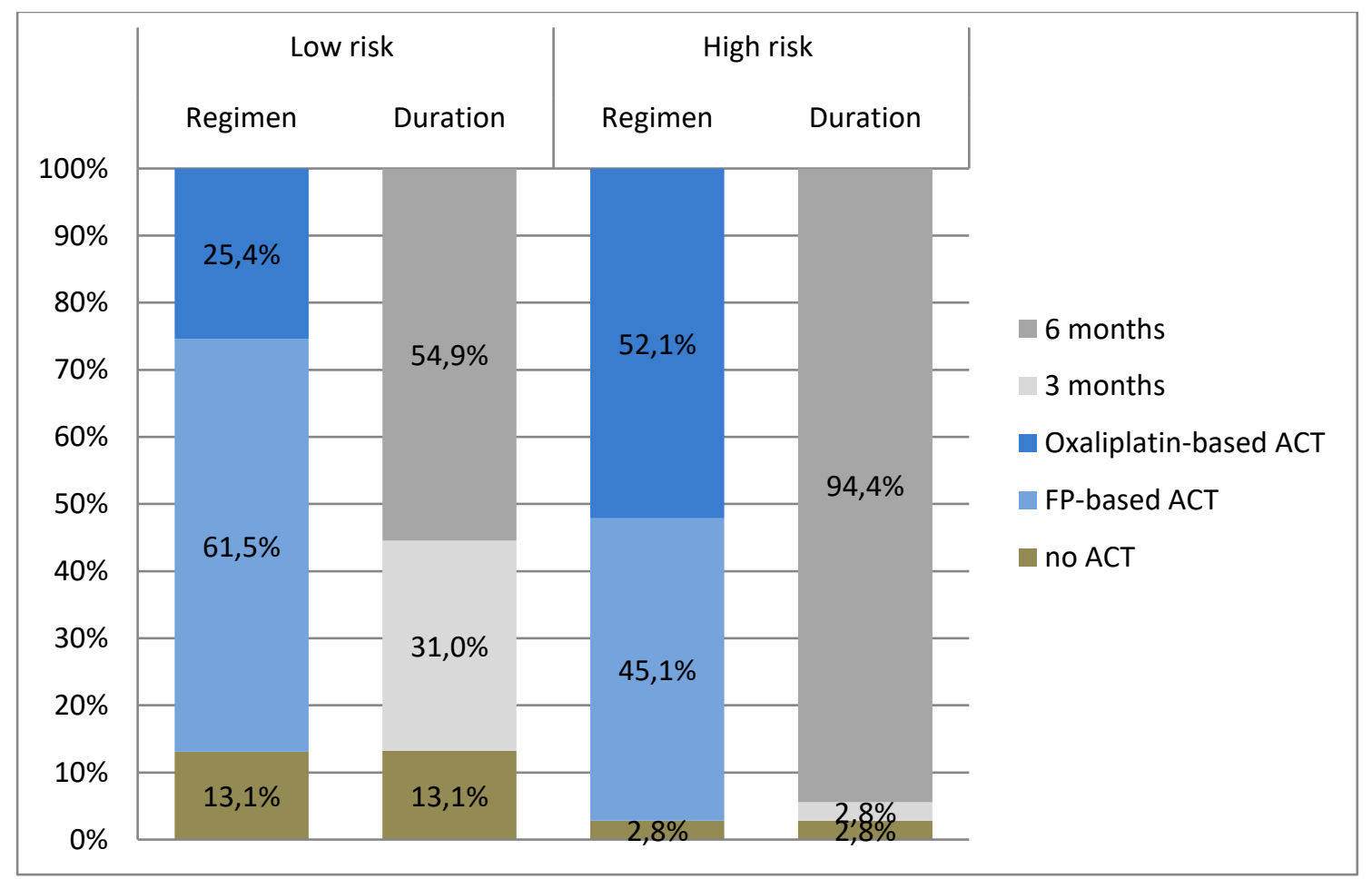




\section{PART I:}

1 / In which region are you working :
A. Auvergne-Rhône-Alpes
B. Bourgogne-Franche-Comté
C. Bretagne
D. Centre-Val de Loire
E. Corse
F. Grand-Est
G. Hauts-de-France
H. Ile-de-France
I. Normandie
J. Nouvelle-Aquitaine
K. Occitanie
L. Pays de la Loire
M. Provence-Alpes-Côte d'Azur
N. DOM-TOM

2/: Do you work :
A. In a teaching hospital
B. In a general hospital
C. In a private health institution of collective interest/Comprehensive cancer center
D. In a private clinic
E. Other

3/ Number of years of practice :
A. $<5$ years
B. Between 5 and 10 years
C. Between 10 and 20 years
D. $>20$ years

4/ What is your speciality :
A. Medical oncologist
B. Radiation oncologist 
C. Gastro-enterologist with an expertise in oncology

D. Surgeon

E. Other

5/ Number of patients with a stade III colon cancer or high rectal cancer that you newly took care of in the last 12 months :
A. $<4$ patients
B. Between 4 and 8 patients
C. Between 8 and 12 patients
D. $>12$ patients

\section{PART II :}

1/ Since the publication of the IDEA study (Grothey, A. et al. Duration of Adjuvant Chemotherapy for Stage III Colon Cancer. N. Engl. J. Med. 378, 1177-1188 (2018)), did you change your practices?

Likert scale from 0 (not at all) à 10 (completely).

\section{Concerning the duration of treatment :}

2/ For the T1-T3 et N1 tumors, concerning the duration of treatment :

A - Yes, 3 months is the new duration for the majority of my patients in this case

B- No

If you answered no, why? (multiple replies are possible) :

$a /$ the study does not allow to conclude non inferiority on its main judgment criteria

$b /$ the analysis of the results by level of risk (stage III of low risk versus high risk) was not planned in the protocol; so I don't think this subgroup analysis is robust enough

$c /$ the analysis of the IDEA France study show that 6 months of FOLFOX6m is better than 3 months of FOLFOX6m, even for the low risk, and I prefer to use FOLFOX

$d /$ Other : Specify [free text]

3/ For the T4 eand/or N2 tumors, concerning the duration of treatment :

A - Yes, 3 months is the new duration for the majority of my patients in this case

B- No

If you answered no, why? (multiple replies are possible) : 
$a /$ the study shows the superiority of 6 month in this subgroup

$b /$ the analysis of the results by level of risk (stage III of low risk versus high risk) was not planned in the protocol and does not allow to conclude statistically at the non inferiority of 3 months vs 6 months, so sub-group analyses don't seem valid to me

$c /$ the analysis of the IDEA France study showing that 6 months of FOLFOX6m is better than 3 months of FOLFOX6m.

$d /$ Other : Specify [free text]

\section{Concerning the treatment regimen :}

4/ For the T1-T3 et N1 tumors, concerning the treatment regimen :

A - Yes, CAPOX is the treatment regimen that I prescribe to the majoriry of my patients in this case, and I prescribe it for 3 months

$\mathrm{B}$ - Yes, CAPOX is the treatment regimen that I prescribe to the majoriry of my patients in this case, and I prescribe it for 6 months

C- No

If you answered no, why? (multiple replies are possible) :

$a /$ the analysis of the IDEA France study shows that 6 months of FOLFOX6m is better than 3 months of FOLFOX6m.

$b /$ I'm rather partial to FOLFOX6m for tolerance reasons.

$c /$ I'm rather partial to FOLFOX6m for observance reasons.

$d /$ Other : Specify [free text]

5/ For the $\mathrm{T} 4$ and/or N2 tumors, concerning the treatment regimen :

A - Yes, CAPOX is the treatment regimen that I prescribe to the majoriry of my patients in this case, and I prescribe it for 3 months

$\mathrm{B}$ - Yes, CAPOX is the treatment regimen that I prescribe to the majoriry of my patients in this case, and I prescribe it for 6 months

C- No

If you answered no, why? (multiple replies are possible) :

$a /$ the analysis of the IDEA France study shows that 6 months of FOLFOX6m is better than 3 months of FOLFOX6m.

$b /$ I'm rather partial to FOLFOX6m for tolerance reasons.

$c /$ I'm rather partial to FOLFOX6m for observance reasons.

$d /$ Other : Specify [free text] 


\section{1/ If this was a stage pT3N1:}

$a /$ What treatment regimen would you propose as first line therapy ?
A- CAPOX
B- FOLFOX

$b /$ For how long?
A- 3 months
B- 6 months

2/ For the last 5 patients under 70 years of age you took care of for a pT3N1, to how many did you prescribe :
A- CAPOX 3 months : (n)
B- CAPOX 6 months : (n)
C- FOLFOX 3 months: (n)
D- FOLFOX 6 months: (n) $[A+B+C+D=5]$

\section{3/ If this was a stage pT3N2:}

$a /$ What treatment regimen would you propose as first line therapy?
A- CAPOX
B- FOLFOX

$b /$ For how long?
A- 3 months
B- 6 months

4/ If this was a stage pT4N1:

$a /$ What treatment regimen would you propose as first line therapy?
A- CAPOX
B- FOLFOX

$b /$ For how long?
A- 3 months
B- 6 months 
5/ If this was a stage pT4N2:

$a /$ What treatment regimen would you propose as first line therapy?
A- CAPOX
B- FOLFOX

$b /$ For how long?
A- 3 months
B- 6 months

6/ For the last 5 patients under 70 years of age you took care of for a pT4 or N2, to how many did you prescribe :
A- CAPOX 3 months : (n)
B- CAPOX 6 months : $(n)$
C- FOLFOX 3 months : ( $n$ )
D- FOLFOX 6 months : (n) $[A+B+C+D=5]$

PART IIIB : In the case of a patient over 70 years of age in good shape (OMS 0 or 1, whithout co-morbidities) with a stage III colon cancer or high rectal cancer treated by surgery:

\section{1/ If this was a stage pT3N1:}

$a /$ What treatment regimen would you propose as first line therapy?
A- Simple monitoring
B- CAPECITABINE
C- LV5FU2
D- CAPOX
E- FOLFOX

$b /$ For how long?
A- 3 months
B- 6 months
C- Not applicable (Simple monitoring)

c/ About the last 5 patients you took care of, how many did you treat with :
A- Simple monitoring: (n)
B- CAPECITABINE : $(n)$
C- LV5FU2 : (n)
D- CAPOX : (n) 


\section{E- FOLFOX : (n) $[A+B+C+D+E=5]$}

$d /$ Based on your chemotherapy prescription data, for those who had chemotherapy, what was the duration of treatment?

Likert scale: Always 3 months / mainly 3 months / as much 3 months as 6 months / mainly 6 months / always 6 months

\section{2/ If this was a stage pT4N2:}

$a /$ What treatment regimen would you propose as first line therapy ?
A- Simple monitoring
B- CAPECITABINE
C- LV5FU2
D- CAPOX
E- FOLFOX

$b /$ For how long ?
A- 3 months
B- 6 months
C - Not applicable (Simple monitoring)

c/ About the last 5 patients you took care of, how many did you treat with :
A- Simple monitoring: $(n)$
B- CAPECITABINE : $(n)$
C- LV5FU2 : (n)
D- CAPOX : (n)
E- FOLFOX : (n) $[A+B+C+D+E=5]$

$d /$ Based on your chemotherapy prescription data, for those who had chemotherapy, what was the duration of treatment?

Likert scale: Always 3 months / mainly 3 months / as much 3 months as 6 months / mainly 6 months / always 6 months

PART IIIC : In the case of a patient over 70 years of age in good shape, but OMS 2 or with comorbidities, with a stage III colon cancer or high rectal cancer treated by surgery :

1/ If this was a stage pT3N1:

$a /$ What treatment regimen would you propose as first line therapy? 

A- Simple monitoring
B- CAPECITABINE
C- LV5FU2
D- CAPOX
E- FOLFOX

$b /$ For how long?
A- 3 months
B- 6 months
C - Not applicable (Simple monitoring)

c/ About the last 5 patients you took care of, how many did you treat with :
A- Simple monitoring: (n)
B- CAPECITABINE : $(n)$
C- LV5FU2 : (n)
D- CAPOX : (n)
E- FOLFOX : (n) $[A+B+C+D+E=5]$

$d /$ Based on your chemotherapy prescription data, for those who had chemotherapy, what was the duration of treatment?

Likert scale: Always 3 months / mainly 3 months / as much 3 months as 6 months / mainly 6 months / always 6 months

\section{2/ If this was a stage pT4N2:}

$a /$ What treatment regimen would you propose as first line therapy ?
A- Simple monitoring
B- CAPECITABINE
C- LV5FU2
D- CAPOX
E- FOLFOX

b/ For how long?
A- 3 months
B- 6 months
C - Not applicable (Simple monitoring)

$c /$ For the last 5 you took care of, how many did you treat with : 

A- Simple monitoring: ( $n$ )
B- CAPECITABINE : $(n)$
C- LV5FU2 : (n)
D- CAPOX : (n)
E- FOLFOX : (n) $[A+B+C+D+E=5]$

$d /$ Based on your chemotherapy prescription data, for those who had chemotherapy, what was the duration of treatment?

Likert scale: Always 3 months / mainly 3 months / as much 3 months as 6 months / mainly 6 months / always 6 months

\section{PART IV:}

1/ a/ During the realization of an adjuvant chemotherapy by CAPOX during 3 months, in case of good clinical venous state, do you preferentially do the treatment on :
A- An importable port
B- A PICC-line
C- A peripheral venous line

$b /$ Of the 5 last patients for whom who prescribe CAPOX for 3 months, to how many did you do the treatment on :
A. An implantable port : $\mathrm{X}$
B. A PICC-LINE : Y
C. Not on a central line : $\mathrm{Z}[X+Y+Z=5]$

2/ a/ During the realization of an adjuvant chemotherapy by CAPOX during 6 months, in case of good clinical venous state, do you preferentially do the treatment on:
B- An importable port
D- A PICC-line
E- A peripheral venous line

$b /$ Of the 5 last patients for whom who prescribe CAPOX for 3 months, to how many did you do the treatment on :
A. An implantable port : $\mathrm{X}$
B. A PICC-LINE : Y
C. Not on a central line : $\mathrm{Z}[X+Y+Z=5]$ 
3/ When you decided to do a chemotherapy by CAPOX on a peripheral venous line,

A- $a$ / In which proportion of the cases you had to secondarily put a central line (an importable port or a PICC-line) during treatment :
A- Less than $25 \%$
B- Between 25 et $50 \%$
C- Between 50 et $75 \%$
D- More than $75 \%$

$b /$ Was it :

Likert scale: Always an importable port / mainly an importable port / as much an importable port as a PICC-line / mainly a PICC-line / always a PICC-line

$c /$ What was the reason for secondary use of a peripheral venous line? [free text]

4/ When you decide to do a chemotherapy by FOLFOX, do you do :
A- FOLFOX6m (1 infuser of 46h)
B- FOLFOX4 (2 infuser of 23h) 